\title{
Meeting the biosecurity concerns of genetically modified organisms (GMOs) through Malaysia's Strategic Trade Act 2010 and Biosafety Act 2007
}

\author{
M. A. Majid \\ School of History, Politics and Strategy, \\ National University of Malaysia, Malaysia
}

\begin{abstract}
Biosecurity has been gaining more prominence in Malaysia. The Food and Agriculture Organization of the United Nations (FAO) defines biosecurity to cover Genetically Modified Organisms (GMOs), pests, diseases and invasive alien species. The loss, threat, misuse, theft, diversion or intentional release of pathogens and toxin producing organisms can be prevented through institutional and security measures constituting the Organization for Economic Cooperation and Development's (OECD's) understanding of biosecurity. The purpose of this paper seeks to examine Malaysia's Strategic Trade Act 2010 and the Biosafety Act 2007 whether both laws are capable of addressing the biosecurity of GMOs in the context of the FAO and OECD's definition of this term. The method relied for this study is qualitative based on an analysis or both primary legislations, Malaysian government documents, information from Malaysian government agencies websites, international organization documents and secondary resources. The results from this study indicate that both laws are capable of addressing biosecurity from both the FAO and OECD's perspectives. The Biosafety Act 2007 is very specific to GMOs while the Strategic Trade Act 2010 covers all biological agents including GMOs. Both laws address bioterrorism in harming humans, plants and animals. However, the Strategic Trade Act 2010 has more stringent requirements in monitoring GMOs for research and contained use compared to the Biosafety Act 2007. In conclusion, both laws are current in meeting the advent of biotechnology, the consequences and threats posed.

Keywords: biosecurity, bioterrorism, genetically modified organisms (GMOs), Biosafety Act 2007, Strategic Trade Act 2010, biological agents, agroterrorism.
\end{abstract}




\section{Introduction}

Biosecurity, another terminology with multiple facets has been interpreted in many ways. The Food and Agriculture Organization of the United Nations (FAO) defines biosecurity as "a strategic and integrated approach that encompasses the policy and regulatory frameworks (including instruments and activities) for analyzing and managing relevant risks to human, animal and plant life and health, and associated risks to the environment" [1]. The FAO's elaboration on biosecurity further adds that its scope encompasses "food safety, zoonoses, the introduction of animal and plant diseases and pests, the introduction and release of living modified organisms (LMOs) and their products, and the introduction and management of invasive alien species" [1]. LMOs in the Cartagena Protocol on Biosafety (CPB) are "any living organism that possesses a novel combination of genetic material obtained through the use of modern biotechnology" [2]. For the purpose of this paper, LMOs will also be understood to mean Genetically Modified Organisms (GMOs) covering both the living and non-living forms of microorganisms being modified through genetic engineering as the latter term is more commonly used. Furthermore, the FAO has extended biosecurity risk management to also cover the economic and social impacts wrought by pests, diseases, introduction of GMOs, invasive alien species, zoonoses and food security [1].

On the other hand, the Organization for Economic Cooperation and Development (OECD) defines biosecurity as "institutional and personal security measures and procedures designed to prevent the loss, theft, misuse, diversion or intentional release of pathogens, or parts of them, or toxin producing organisms, as well as toxins that are held, transferred and/or supplied by Biological Resource Centres (BRCs)" [3]. It is the position in this paper that both definitions of biosecurity are complementary and exist with each other. This is in view of the dual use of life sciences defined by the World Health Organization (WHO) as the "knowledge and technologies generated by legitimate life sciences research that may be appropriated for illegitimate intentions and application" [4]. The WHO's definition of the dual use life sciences seems appropriate as it captures genetic modification technology used to produce GMOs and being utilized either for the good of humankind or for malicious purposes as highlighted by the OECD's definition of biosecurity.

Based on the above definitions of biosecurity, a review will be made regarding the extent that Malaysia has addressed biosecurity in the context of GMOs. An overview of biosecurity without specifically focusing on GMOs has shown that it has been given a very low priority by Malaysia [5]. On a larger geographical scale, Minehata [6] has asserted that the Asia-Pacific region covering Malaysia has given more priority towards agricultural security, biodiversity and public health in the context of biosecurity. Minehata [6] has stressed that a low priority has been given towards biosecurity in the national security sense concerning biological weapons or dual use issues in the AsiaPacific region. From this review, it is apparent that the Asia-Pacific region including Malaysia has disregarded the biosecurity aspect emphasized by the 
OECD by paying scant attention to biological agents that may be lost, stolen, misused, diverted or intentionally released into the environment to cause harm to plants, animals, humans and other organisms. Based on the above review, this paper has the purpose of challenging the above assumptions by analyzing Malaysia's Biosafety Act 2007 and Strategic Trade Act 2010 to assess whether this country has adequate laws to address the biosecurity of GMOs specifically from the perspective of the FAO and OECD.

\section{Methods}

For undertaking the task in this paper, the method relied for this study is one that is qualitative. A comparative analysis of both primary legislations as mentioned above regarding their similarities and differences will be conducted. This will be supported by other Malaysian government documents, information from Malaysian government agencies websites, international organization documents and secondary resources that will be referred.

\section{Comparing the Biosafety Act 2007 and Strategic Trade Act 2010}

In making a comparison between both the Malaysian laws as mentioned above, Section 3.1 will first examine the objective of both laws while Section 3.2 will identify the parties protected by these laws. Section 3.3 will discuss whether both these laws are able to meet the biosecurity scope proposed by the FAO. An examination of whether both Malaysian laws have fulfilled the OECD's definition of biosecurity will be undertaken in Section 3.4 to be followed by the conclusion.

\subsection{The objective of both laws}

This section compares the objective of both laws mentioned above to monitor the biosecurity of GMOs. The preamble of Malaysia's Biosafety Act 2007 has the purpose of regulating the importation, exportation and contained use of GMOs with the objective of protecting humans, plants, animal health, the environment and biological diversity [7].

In comparison, the preamble of Malaysia's Strategic Trade Act 2010 provides control over the export, transhipment, transit and brokering of strategic items, including arms and related materials, and other activities that may facilitate the design, development and production of Weapons of Mass Destruction (WMDs) and their delivery system [8]. Section 2 of the Strategic Trade Act 2010 defines WMD as "any weapon designed to kill, harm or infect people, animals or plants through the effect of [...] the infectious or toxic properties of a biological weapon, and includes a delivery system designed, adapted or intended for the deployment of such weapons" [8]. The same provision of this law defines a biological weapon as "any microbial or other biological agents or toxins whatever their origin or method of production, of types and in quantities that 
have no justification for prophylactic protective or other peaceful purpose, and weapons, equipment or means of delivery designed to use biological agents or toxins for hostile purposes or in armed conflict" [8]. In turn, biological agents in the same provision of the same law are defined as any "microbial, microorganisms, virus or infectious substance derived from them naturally or artificially, as well as their components" [8]. Since biological agents also cover those that are artificially derived, this would encompass GMOs as they are genetically engineered by humans spanning across species.

While the Biosafety Act 2007 is very specific in regulating GMOs merely, it is apparent that the Strategic Trade Act 2010 not only will regulate GMOs but other biological agents too including those naturally occurring in nature but both would address the exportation of GMOs as mentioned in their preamble earlier. Section 22(1) (a) of the Biosafety Act 2007 merely requires a notification for the exportation of GMOs to Malaysia's National Biosafety Board (NBB) [7]. Although the Biosafety Act 2007 does not define export, the Strategic Trade Act 2010 in Section 2 defines export as "to take or cause to be taken out of Malaysia any items by land, sea or air, or to place any items in a conveyance for the purpose of such items being taken out of Malaysia" [8]. A conveyance in Section 2 of the Strategic Trade Act 2010 covers any "vessel, train, vehicle, aircraft and any other means of transport by which persons or items can be carried" [8].

In contrast to Malaysia's Biosafety Act 2007, Section 9(1) of the Strategic Trade Act 2010 is far more restrictive regarding the export, transhipment and transit of strategic items that includes biological agents requiring a permit unlike a mere notification in the former law in Section 22(1) [7, 8]. Likewise, there is also a limitation for the exportation, transhipment or bringing into transit any strategic or unlisted items to a restricted end user as will be determined by Malaysia's Minister of International Trade and Industry (MITI) in Section 9(2) of the Strategic Trade Act 2010 [8]. A restricted end user is an individual involved in "any activity that supports the development, production, handling, usage, maintenance, storage, inventory or proliferation of any WMDs and its delivery systems" in Section 8(1) of the Strategic Trade Act 2010 [8]. It then arises that an exporter will have to comply with both laws even though there is a conflict between them. In fact, Section 2(1) of the Biosafety Act 2007 provides that this law can also be read with other written laws implying that it can apply simultaneously with the Strategic Trade Act 2010 [7]. However, Section 2(2) of the Biosafety Act 2007 and Section 3(2) of the Strategic Trade Act 2010 have similar provisions stating that in the event of a conflict with another law, either the former or the latter will not be subordinated to other laws $[7,8]$. This raises an important issue because if there is a conflict between both the Biosafety Act 2007 and the Strategic Act 2010 which law would eventually take precedence over the other.

Based on the above, it comes as no surprise that the Strategic Trade Act 2010 has stricter requirements for the exportation of GMOs in their usage as biological weapons as its preamble safeguards Malaysia's national security whereas the Biosafety Act 2007 is more concerned with GMOs in agriculture. 


\subsection{Parties protected by both laws}

Apart from the above, it is also crucial to analyze the relevant parties that the Biosafety Act 2007 and Strategic Trade Act 2010 seek to protect. The preamble of the Biosafety Act 2007 has the objective of "protecting human, plant and animal health, the environment and biological diversity" [7]. Likewise, the Strategic Trade Act 2010 in Section 2 is equally concerned with the impact of WMDs "to kill, harm or infect people, animals or plants through [...] the infectious or toxic properties of a biological weapon" [8]. In this sense, both laws are targeting to protect the same parties likely to be harmed by GMOs but the Biosafety Act 2007 protects more components like the environment and biological diversity.

The protection of the parties concerned also shows whether both laws protect them from bioterrorism harming humans merely or agroterrorism too. Agroterrorism is defined as the "deliberate introduction of plant and animal disease to create a climate of fear, damage the economy, undermine public order and stability" [9]. By both laws seeking to protect plants and animals, this means a protection against agroterrorism mainly carried out as an economic sabotage. GMO seeds may be dispersed in an open field or plantation without easy detection. The acres of land uneasily monitored invites intruders to trespass and conduct their malicious deed of genetically contaminating conventional or organic crops causing farmers planting these crops to lose their income.

Another difference between the Biosafety Act 2007 and Strategic Trade Act 2010 regards the protection of the parties concerned either in a peaceful, hostile or armed conflict situation. Section 2 of the Strategic Trade Act 2010 provides a justification for biological weapons for prophylactic, protective or peaceful purposes merely while this is prohibited in the situation of armed conflict or hostile situations [8]. This shows the potential of genetic modification technology and its product, GMOs being used in two situations, either for peaceful purposes such as the good of agriculture, for hostile or in armed conflict situations bringing about the dual use life sciences concern. In contrast, the Biosafety Act 2007 does not distinguish between whether GMOs should be produced merely for peaceful purposes, for hostile or armed conflict situations. Presumably, as long as harm is caused to humans, plants, animals, the environment and biological diversity, the Biosafety Act 2007 applies in protecting all of these parties regardless of any situation.

\subsection{Meeting the scope of biosecurity highlighted by the FAO}

In recapitulating, the FAO's scope of biosecurity covers the concern for diseases, pests, invasive alien species, food safety and GMOs [1]. This section will investigate whether GMOs can cause diseases, act as pests, are invasive alien species and have food safety concerns. In turn, this will be tied with both Malaysia's laws mentioned earlier.

It will be examined whether GMOs excreting toxins can indeed become pests. In the European Communities Measures affecting the approval and marketing of Biotech Products case law or in short the EC-Biotechnology case, GMO plants 
that are insect resistant are normally implanted with a toxin specifically targeting a particular pest with the intention of controlling or eradicating the pest [10]. The Panel in paragraph 7.370 of the EC-Biotechnology case interpreted the term "pest" as "a troublesome, annoying or destructive person, animal or thing" [10]. The Panel in paragraph 7.323 of this same case determine that "a poisonous substance which is produced during the metabolism or growth of a [Genetically Modified] GM crop could qualify as a 'toxin' within the meaning of Annex A (1)(b) of the Sanitary and Phytosanitary (SPS) Agreement" of the World Trade Organization (WTO) [10]. While GMO crops with pest resistance to target pests may benefit agriculture, it may cause dire consequences or kill non-target organisms that choose these crops as a source of food. In this regard, the Panel in paragraph 7.269 of the EC-Biotechnology case noted that GMO crops may be "considered as 'pests' if they are associated with adverse effects on non-target organisms" [10]. If GMO crops are to be regarded as pests, it is through GMO pest resistance crops with inbuilt toxins that kill non-target organisms as illustrated. In Section 2 of Malaysia's Strategic Trade Act 2010, toxin refers to "any poisonous substance, whatever its origin of method of production produced by a living organism or artificially synthesized which can cause illness, injury or death" [8]. Since GMO crops are artificially synthesized and produce toxins, the Strategic Trade Act 2010 would cover GMO pest resistance crops with inbuilt toxins based on the EC-Biotechnology case.

Yet another example illustrating that GMO crops can be regarded as pests is shown through the allergic response of farmers exposed to GMO crops. In paragraph 7.350 of the EC-Biotechnology case, the Panel considered that GMO crops could produce allergen effects other than in food to cause harm to human health to be regarded as pests [10]. This occurs when farmers come into contact with GMO crops in a field, or any individual passing through the field are allergic to the substance produced by GMO crops [10]. The EC-Biotechnology case also highlighted the possible immediate or delayed effects impacting human health from the direct or indirect interactions of releases from the Genetically Modified Higher Plants (GMHP) [10]. The Panel in paragraph 7.362 of the said case pronounced that such a measure in addressing occupational safety and health hazards would fall under Annex A(1)(c) of the SPS Agreement [10]. Annex A(1)(c) of the SPS Agreement intends "to protect human life or health within the territory of the Member from risks arising from diseases carried by animals, plants or products thereof, or from the entry, establishment or spread of pests" [11].

As another illustration that GMO crops are a form of pest, Annex A of the SPS Agreement mentions that "pest" encompasses weeds [11]. Weeds referred to plants. The Panel in paragraph 7.239 further elaborated that a "pest" could "destroy the life and threaten the very existence of other animals, plants or humans" [10]. It has been considered in paragraph 7.245 of the ECBiotechnology case that GMO plants growing in undesired places as a result of seed spillage or invasiveness to be regarded as pests [10]. In this regard, the ECBiotechnology case in paragraph 7.247 determine that GMO crops are not only weeds when they grow at unwanted places but are invasive alien species when 
genetic contamination occurs at centres of origin [10]. The Panel in paragraph 7.245 considered that "volunteer [Genetically Modified] (GM) plants growing in the fields of conventional plants might be considered to be undesirable plants and hence 'pests', or 'weeds' from the perspective of the farmer seeking to grow a crop other than the unwanted GM crops" [10]. Therefore, it has been shown through the various examples as indicated regarding the means for GMO crops to be pests.

Apart from GMOs being pests, there is also the potential for GMOs to indirectly contribute as a disease causing organism. In the EC-Biotechnology case, the Panel in paragraph 7.281 raised the concern regarding the "potential transfer of pathogens of [the Antibiotic Resistance Marker Genes (ARMG)] present in certain GMOs" [10]. This relates to the ARMG in paragraph 7.303 of the EC-Biotechnology case being introduced into GMO crops in detecting whether "cells into which another foreign gene is inserted have actually taken up that gene" [10]. The Panel in paragraph 7.304 of the EC-Biotechnology case stressed that the ARMG may be transferred to pathogens causing antibiotic resistance in the digestive human and animal gut [10]. Paragraph 7.304 of the said case reiterated if pathogens are to develop resistance to antibiotics, this may endanger and cause a risk to human or animal life or their health [10]. The Panel in paragraph 7.304 of this case viewed that antibiotic resistance compromises the effectiveness of medical or veterinary treatment for diseases [10]. GMO crops or the ARMG are not to be regarded as disease causing organisms in this case but the pathogens developing the resistance to ARMG are classified as disease causing organisms [10]. If humans are to consume any food containing the ARMG causing them to develop antibiotic resistance, this brings about food safety concerns with regard to GMO food.

Based on the above analysis, it has clearly been shown that GMOs may be pests, invasive alien species, having toxicity qualities, indirectly are disease causing organisms and have food safety concerns. These would all fit into the FAO's scope of concern for biosecurity. However, neither does Malaysia's Biosafety Act 2007 nor its Strategic Trade Act 2010 directly mention the consequences of GMOs becoming pests, invasive alien species, are disease causing organisms or having food safety concerns. As already illustrated, GMOs that are pests can harm plants and kill non-target insects while the ARMG affects animals and human health. Since both the Biosafety Act 2007 and Strategic Trade Act 2010 seek to protect or is concerned that GMOs as biological weapons would harm or kill people, plants and animals, indirectly this would address GMOs as pests, disease causing organisms and having food safety implications as implied by the EC-Biotechnology case.

\subsection{Fulfilling the OECD's definition of biosecurity}

As recalled earlier, the OECD's definition of biosecurity is one concerned with the institutional and personal security measures to prevent the loss, theft, misuse, diversion or intentional release of pathogens or parts of them or toxin producing organisms [3]. This section will examine the extent that Malaysia's Biosafety 
Act 2007 and Strategic Trade Act 2010 would meet the biosecurity concerns highlighted by the OECD as mentioned above.

The investigation begins by examining Malaysia's treatment of GMOs for contained use. Section 22 of the Biosafety Act 2007 has a very weak provision for contained use and import for contained use in the laboratory as all that is required is a notification to the NBB [7]. Such a provision can be misused by a terrorist to easily import GMOs as a biological weapon under the pretext of research, further develop it through GMO technology in a contained facility without being caught easily to exploit this weakness in the Biosafety Act 2007. If GMOs are to be misused as highlighted in the OECD's definition of biosecurity, this would be such an example whereby GMOs may be imported with the pretext of doing research but in the end developed in a research facility to be, secretly, a biological weapon. If the misuse of GMOs is to be prevented, this must certainly start at Malaysia's borders even for an importation that may just be used for research. Malaysia's scientists though would abhor such a ruling as they may argue that this will prevent any useful research to spur biotechnology in the country. In contrast, the Strategic Trade Act 2010 requires an examination whether the research to be carried out would fall under the import control restrictions and this would require approval from the Strategic Controller of MITI [12]. Therefore, the Strategic Trade Act 2010 has a much more stringent requirement for the development of GMOs as contained use. Since Section 2(1) of the Biosafety Act 2007 provides that this law can also be read with other written laws like the Strategic Trade Act 2010, a person wanting to import GMOs for research may have to obtain the approval from the Strategic Controller of MITI even though the Biosafety Act 2007 may be quite lax in this regard [7].

Aside from monitoring GMOs at a country's borders, the biosecurity of GMOs must also be concerned about GMOs being stolen or lost within a contained facility. In particular, Section 9(2) (d), (e) and (i) of Malaysia's Biosafety (Approval and Notification) Regulations 2010 requires the NBB to monitor all Institutional Biosafety Committees (IBCs) established in organizations conducting GMO research to have record keeping requirements, the required level of containment with respect to a GMO activity as well as auditing and reporting that requires an organization to put certain conditions for the entry into premises where GMO research is conducted [13]. The introduction of the said Regulations to the Biosafety Act 2007 means that this law is now fully implemented and must be strictly adhered to. Besides the Regulations, there are two guidelines assisting to operationalize the Regulations called the Biosafety Guidelines for Contained Use Activity of Living Modified Organisms (LMOs) and the Guidelines for Institutional Biosafety Committees: Use of Living Modified Organisms and Related Materials both issued in 2010 [14, 15].

In indicating that Malaysia now has more stringent rules for GMOs used in a contained facility, some examples of constructive efforts in the Biosafety Guidelines for Contained Use Activity of Living Modified Organisms (LMOs) will be mentioned. Any GMO experiment with moderate risk having containment level 3 (BSL3) requires a separation of the lab from other areas 
including offices not easily accessible to the public [14]. Having a secluded location will certainly make it harder for anyone with a malicious intent to steal any GMOs easily. Another crucial security feature of a BSL3 facility requires that one side of the laboratory wall have a glass panel or observation window to view laboratory occupants from the outside or to have alternative closed circuit televisions (CCTV) in monitoring individuals entering and their activities in the laboratory [14]. As far as work practice in a BSL3 laboratory is concerned, only authorized persons having knowledge of biohazards and meeting the relevant medical requirements will have access [14]. As a biosecurity measure, this will limit the number of individuals entering a BSL3 laboratory and if any GMOs are lost or stolen, it will certainly be easier to trace the culprit. Furthermore, the BSL3 laboratory door should be locked at all times when unused to prevent any theft or unauthorized persons from entering [14].

In the case of a laboratory involving high risk categorised as containment level 4 (BSL4), most of the biosecurity measures are far more stringent. For instance, any personnel providing support services to the BSL4 laboratory must be accompanied by an authorized person [14]. This is to prevent an outsider from stealing any microorganisms for any malicious intent. Moreover, any personnel entering the BSL4 laboratory must sign a log book indicating the date and time of entry and exit [14]. This provides a record to trace any individual should it be found that any GMOs are stolen from the BSL4 facility.

As additional biosecurity features, the other following requirements must also be met. In the transportation of GMOs, adequate records must also be kept detailing the movement of GMOs between research and storage facilities as well as field trial sites [14]. Another control measure includes the need for a shipper to notify the receiver of the date, kind and amount of material to be shipped before the shipping process ever begins [14]. The receiver upon receiving the consignment will have to check that all materials are intact and none are lost [14]. This way, if any GMOs are lost or stolen, a series of events and the record of the handlers provide the relevant information for traceability.

Likewise, precautionary measures for the storage of GMOs and related materials are crucial for biosecurity. In this context, there is a requirement that all storage areas be labelled as containing GMOs and there must be a restriction for authorized personnel only [14]. Besides this, keeping an inventory of all GMOs in storage is required while its removal for experimental purposes must be recorded [14]. There is also a requirement for inspections to be undertaken and recorded with regard to the storage areas of GMOs to avoid any unintentional release [14]. The integrity of material packaging should also be a priority during the inspection process to ensure that no tampering occurs [14]. Similarly, the Guidelines for Institutional Biosafety Committees: Use of Living Modified Organisms and Related Materials also requires members of the IBCs together with representatives authorized by the NBB to conduct routine inspections for registered laboratories with GMO materials to ensure that laboratory standards are complied [15]. The principal investigator (PI) in an organization conducting GMO experiments must also conduct a risk vulnerability assessment to protect the security of GMOs [15]. Among the 
additional efforts the PI should take include measures in having locks for laboratory doors and freezers where GMOs may be stored [15]. The PI also has to address the loss of keys, passwords, other secured information and materials besides complying with all the other requirements already highlighted in the Biosafety Guidelines for Contained Use Activity of Living Modified Organisms (LMOs) as above [14]. If all of these measures are not followed, an IBC can recommend the suspension of a project approval for the possession and use of GMOs that may threaten the health and safety of the community [15]. Hence, the above shows some of the steps to be taken by organizations to prevent the theft, misuse and loss of GMOs in a contained use facility in Malaysia as highlighted by the OECD's definition of biosecurity.

\section{Conclusion}

In conclusion, this paper explored whether Malaysia's Biosafety Act 2007 and Strategic Trade Act 2010 have been able to address the biosecurity aspects put forth by the FAO and OECD. It has been shown that both these laws can address the scope of biosecurity highlighted by the FAO whereby GMOs could be pests, as invasive alien species, are disease causing organisms and having food safety implications that Minehata [6] exerts is the biosecurity aspect covering agricultural security, biodiversity and public health that the Asia-Pacific region concentrates upon covering Malaysia too. Both laws with the newly formulated Regulations and Guidelines to the Biosafety Act 2007 especially have also been able to address the OECD's concern of biosecurity regarding the institutional and personal security measures as well as procedures preventing the loss, theft, misuse, diversion and intentional release of pathogens as in the case of GMOs in Malaysia. This refutes Minehata's [6] claim that countries like Malaysia, being part of the Asia-Pacific region have paid scant attention to biosecurity threats endangering the national security of Malaysia for fear that GMOs could be stolen, misused or lost to be utilized as biological weapons. At least, this is especially true for the case of the biosecurity of GMOs specifically in Malaysia meeting the concerns of the OECD. Therefore, it can be said that Malaysia is slowly making progress in addressing biosecurity at least in the context of GMOs to refute claims made by Ahn and York [5] that biosecurity has been given a low priority in Malaysia.

\section{References}

[1] FAO Biosecurity Toolkit; Italy, Food and Agriculture Organization of the United Nations, Online. ftp.fao.org/docrep/fao/010/a1140e/e1140e01.pdf.

[2] Cartagena Protocol on Biosafety to the Convention on Biological Diversity, May 15-26 2000, 39 ILM 1027 (entered into force 11 Sept. 2003).

[3] OECD Best Practice Guidelines on Biosecurity for BRCS; France, Organisation for Economic Co-Operation and Development, Online. www.oecd.org/datooecd/6/27/38778261.pdf. 
[4] Responsible Life Sciences Research for Global Health Security: A Guidance Document; Switzerland, World Health Organisation, Online. whqlibdoc.who.int/hq/2010/WHO_HSE_GAR_BDP_2010.2_eng.pdf

[5] Ahn, M. J. and York, A.S., Resource-based and institution-based approaches to biotechnology industry development in Malaysia. Asia Pacific Journal of Management DOI10.1007/S10490-009-9147-2 (2009) www.springerlink.com/content/0371562317314852/fulltext.pdf.

[6] Minehata, M., An investigation of biosecurity education for life scientists in the Asia-Pacific region; University of Exeter and University of Bradford, Online. 2010. www.brad.ac.uk/bioethics/media/SSIS/Bioethics/docs/ Asia_Pacific_Biosec_Investigation.pdf.

[7] Biosafety Act 2007, No. 678, (2007) (Malaysia).

[8] Strategic Trade Act 2010, No. 708 (2010) (Malaysia).

[9] Agroterrorism: Threats and Preparedness; United States. CRS Report for Congress, Congressional Research Service. 2007. Order Code RL 32521.

[10] World Trade Organization. 2006. European Communities- Measures Affecting the Approval and Marketing of Biotech Products. WTO Doc WT/DS291/R, WT/DS292/R, WT/DS293/R (Reports of the Panel) (Thereafter 'EC-Biotechnology').

[11] Sanitary and Phytosanitary Agreement, Apr. 15 1994, 1867 UNTS 493 (entered into force 1 Jan.1995).

[12] Strategic Trade Act 2010 Frequently Asked Questions; Malaysia, Ministry of International Trade and Industry, Online. www.miti.gov.my/cms /content.jsp?id=com.tms.cms.article.Article.

[13] Biosafety (Approval and Notification) Regulations 2010.

[14] Biosafety Guidelines for Contained Use Activity of Living Modified Organisms (LMO); Malaysia, Department of Biosafety, Online. bch.cbd.int/database/attachment/?id=11641.

[15] Guidelines for Institutional Biosafety Committees: Use of Living Modified Organisms and Related Materials; Malaysia, Department of Biosafety, Online. ibc.um.edu.my/images/ibc/IBC\%GUIDELINES.pdf. 